www.jmscr.igmpublication.org Impact Factor 5.244

Index Copernicus Value: 83.27 ISSN (e)-2347-176x ISSN (p) 2455-0450 crossref DOI: https://dx.doi.org/10.18535/jmscr/v4i12.132

Journal Of Medical Science And Clinical Research

\title{
A Study on Clinical Presentation and Outcome of Concurrent Malaria and Dengue Infection from a Malaria Endemic Zone of North India
}

\author{
Authors \\ Rajendra Kumar Verma ${ }^{1}$, Richa Giri ${ }^{2}$, Nirmala Singh ${ }^{3}$, Chirag Gupta ${ }^{4}$, Arisht Jain ${ }^{5}$ \\ ${ }^{1}$ Assistant Professor, Department of Internal Medicine, GSVM Medical College, Kanpur, India- 208002 \\ Email: rkv45anand@gmail.com,0917499339329 \\ ${ }^{2}$ Professor and Head, Department of Internal Medicine, GSVM Medical College, Kanpur, India- 208002 \\ Email: richa227@ rediffmail.com,0918400331045 \\ ${ }^{3}$ Clinical Practitioner, Pediatrics, Naman Clinic, Kanpur, India- 208002 \\ Email: nirmal214singh@yahoo.com,0917839261937 \\ ${ }^{4}$ Junior Resident, Department of Internal Medicine, GSVM Medical College, Kanpur, India- 208002 \\ Email: drchiragguptal @gmail.com,0918755488009 \\ ${ }^{5}$ Junior Resident, Department of Internal Medicine, GSVM Medical College, Kanpur, India- 208002 \\ Email: Jainarisht89@mail.com,0919616476455
}

\begin{abstract}
This study has been done to differentiate clinical and biological parameter of co-infections from infections alone and to find out whether patients infected by both malaria and dengue were more severe than either infection alone.
\end{abstract}

Material and Methods: All febrile adult patients (> 18 years of age) were investigated for malaria, dengue and other causes of fever. Patients of concurrent dengue and malaria (Group A) were compared with malaria mono-infection (Group B) and dengue mono-infection (Group C). Frequencies of alterations in clinical, biochemical, haematological parameters and outcome were determined in various groups. Data was analysed using appropriate statistical tests.

Results: Out of these 340 patients, there were 52 (15.29\%), 132 (38.82\%), and 156 (45.88\%) patients in Groups A, B, and C respectively. Prevalence of co-infection in our study was $25 \%$. Features like prolonged fever (7.18+/- 3.91), severe anemia (23.07\%) and respiratory distress (7.69\%) were comparable to malaria mono-infection whereas features like bleeding manifestations(15.38\%), frontal or retro-orbital headache (80\%), arthralgia (15.38\%) and / elevated haematocrit were more like dengue mono-infection.

Conclusion: In endemic areas for dengue and malaria, prolonged fever, severe anemia and respiratory distress (in dengue patients) and bleeding manifestations, frontal or retro-orbital headache, arthralgia and / elevated haematocrit level (in malaria patients) should raise the suspicion of co-infection and since a high prevalence of co-infection was found in our geographical area. We recommend that all the patients suspected for dual infections should be treated concomitantly for dengue and malaria in malaria endemic areas.

Keywords: Malaria, Dengue, Co infection, India. 


\section{Introduction}

Dengue fever and malaria are the two most common arthropod-borne diseases in India and they represent major public health problem. Dengue virus (family Flaviridae, genus Flavivirus) and Plasmodium parasites are widespread in Asian tropical regions. The former is a viral disease transmitted by Aedes mosquito and the latter is a parasitic disease transmitted by Anopheles mosquito. In a geographical area where both the vectors co-exist, simultaneous occurrence of dengue and malaria in an individual cannot be ruled out. Our region is situated on the bank of Ganges River and therefore there are lots of marshy places which provide excellent places for mosquito breeding, besides this there is unplanned urbanization with unchecked construction activeities and poor sanitation facilities that contribute to fertile breeding grounds for mosquitoes

Studies on concurrent infections are scarce. Since the first case reported in $2005^{[1]}$, only few casereports and studies have been published. They have been reported with Plasmodium falciparum and/or Plasmodium vivax in India and Pakistan ${ }^{[2-7]}$, Southeast Asia ${ }^{[8][9]}$ French Guiana ${ }^{[10][11]}$ and Brazil [12] [13] [14].

The very first report of existence of dengue fevers in Kanpur was way back in 1968 and $69^{\text {[15][16]. }}$ Thereafter, for the next 40 years, there was no significant dengue activity reported in and around Kanpur. But in last 6 years dengue epidemic is occurring every alternate year. Malaria is endemic in Kanpur with P. vivax being the predominant species. This finding is supported by the data of NVBDC 2015 which reported the presence of only 351(0.85\%) P .falciparum cases out of total 41264 malaria cases in Uttar Pradesh, the state where our institution is situated ${ }^{[45]}$. There is insufficient data on the severity of co-infections worldwide and none from our region, therefore, the aim of this study was to differentiate clinical and biological parameter of co-infections from infections alone and determine whether patients infected by both malaria and dengue were more severe than either infection alone.

\section{Material \& Methods}

\subsection{Setting and Selection Criteria}

This was a prospective observational study conducted in the K P S Institute of Medicine, GSVM Medical College, Kanpur from July 2015 to Nov 2015. It is a tertiary care teaching hospital and provides a full range of medical, surgical and super specialty facilities.

Inclusion Criteria: All Febrile adult (>18yrs) patients admitted in the department were screened for malaria, dengue and other causes of fever and those positive for malaria and/or Dengue were included in the study.

Exclusion Criteria: Following patients were excluded from the study: Pregnant females, patients with age less than 18 yrs, typhoid, kalaazar, Bacterial and viral meningitis, HIV/HbSag positive patients, abnormal liver function test due to hepatotoxic drugs or any other cause, abnormal renal function test in acute or chronic renal failure due to any other cause, bleeding diathesis and patients with $P$. vivax infection with primaquine-induced hemolysis.

\subsection{Malaria and Dengue Diagnosis}

Briefly, 4 to $6 \mathrm{ml}$ of blood was collected from each patient by nursing personnel, male orderlies or physicians using strict aseptic precautions and serum was collected using standard methods. All the samples were collected after obtaining the informed consent from the patients.

Malaria was diagnosed, and the species and number of parasites determined on Giemsa stained thick and thin peripheral blood films examined under oil immersion. A slide was considered negative when there were no parasites in the 100 high power fields. Each blood film was reviewed by two experienced microscopists. For the diagnosis of dengue, Serum collected was tested for IgM and IgG anti dengue antibodies by Dengue IGM capture enzyme linked immune sorbent assay (MAC ELISA) and IgG MAC ELISA (Panbio Pty limited, Queensland, Australia) rapid diagnostic test. 
After diagnosis, patients were grouped into dengue and malaria co-infection (Group A), malaria mono-infection (Group B) and dengue mono-infection (Group C).

\subsection{Clinical and laboratory assessment}

After the diagnosis, Clinical evaluation was done by a physician. The patient demographics and clinical details were recorded in a standard proforma. These included name, age, sex, address, symptoms and signs of the patients. Other standard evaluation included assessment of blood pressure, axillary temperature, systemic examination and description of the other general examination of the patients. Complications and outcome of every patient was also noted. A complete blood count, RBS, liver function test, renal function test, serum electrolytes, USGabdomen, were done in all patients.

\subsection{Statistical Analysis}

Data was compiled using Microsoft Excel. Percentages, proportion were calculated. $\chi^{2}$ was used as test of significance.

\section{Results}

A total of 340 febrile patients with malaria and / dengue positive were admitted in the medicine department of GSVM Medical college, out of these 340 patients, concurrent infection of dengue and malaria was found in 52 patients(Group A), malaria mono-infection in $132(38.82 \%)$ patients (Group B), and dengue mono-infection in 156 (45.88\%) patients(Group C).

Of total 340 patients $256(75.29 \%)$ cases were males and 84(24.70\%) were females.

Similar was the finding in all the three groups too as shown in the table below.

Table 1. Distribution of cases in various groups based on sex and residence.

\begin{tabular}{|l|c|c|c|c|c|c|}
\hline & $\begin{array}{c}\text { GROUP A } \\
\text { (Co- } \\
\text { infection) }\end{array}$ & $\begin{array}{c}\text { GROUP B } \\
\text { (Malaria) }\end{array}$ & $\begin{array}{c}\text { GROUP C } \\
\text { (Dengue) }\end{array}$ & \multicolumn{3}{|c|}{ P - Value } \\
\cline { 2 - 6 } & $\mathrm{N}=52$ & $\mathrm{~N}=132$ & $\mathrm{~N}=156$ & All groups & $\begin{array}{c}\text { Malaria vs. co- } \\
\text { infection }\end{array}$ & $\begin{array}{c}\text { Dengue vs. co- } \\
\text { infection }\end{array}$ \\
\hline MALE & 40 & 88 & 128 & 0.01 & 0.1733 & 0.4164 \\
\hline FEMALE & 12 & 44 & 28 & & 0.1711 & 0.5008 \\
\hline URBAN & 16 & 28 & 56 & 0.0237 & & \\
\hline RURAL & 36 & 104 & 100 & & & \\
\hline
\end{tabular}

Graph 1. Distribution of patients in various groups based on their age

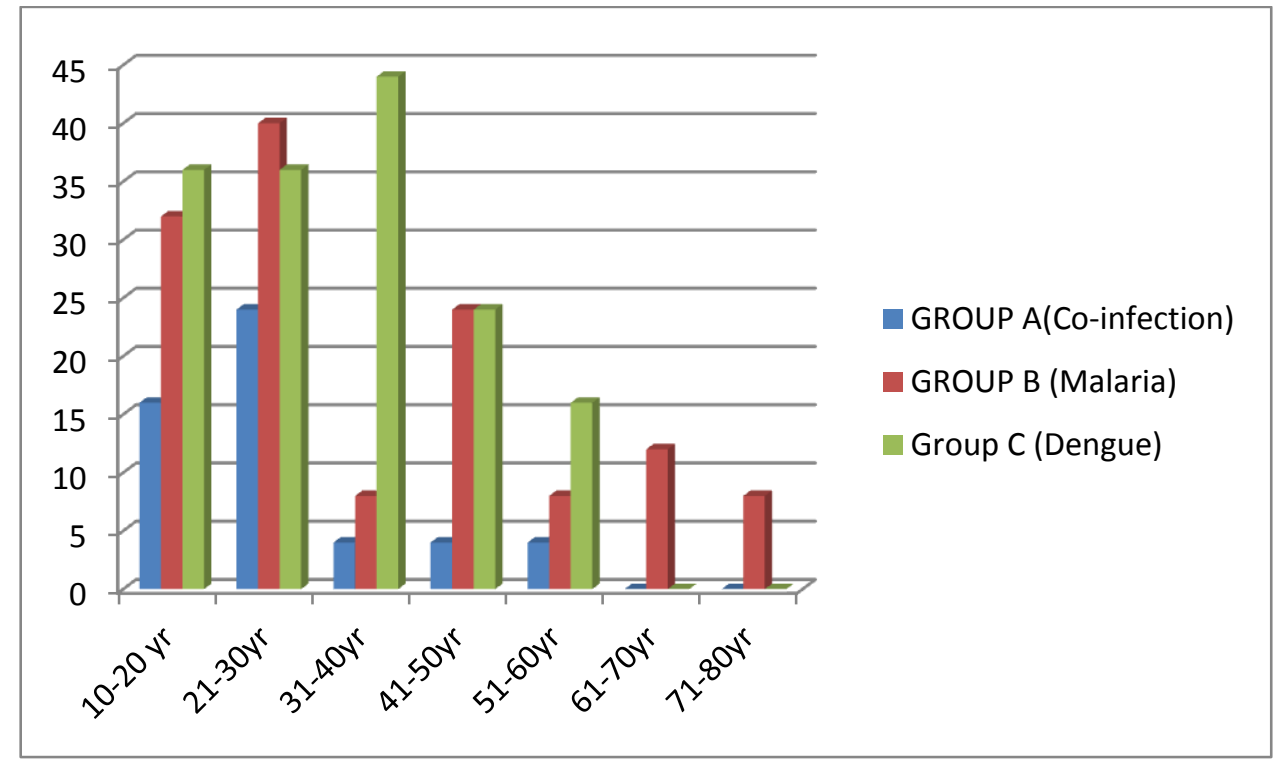


$100(29.41 \%)$ cases were from urban area while $240(70.58 \%)$ were from rural areas. In all the three groups $[\mathrm{A}=36(69.23 \%), \mathrm{B}=104(78.78 \%)$, $\mathrm{C}=100(64.10 \%)]$ majority of the patients hailed from rural areas.

Out of 340 patients fever was present in all patients (100\%) followed by headache in $67.05 \%$ and body ache in $48.23 \%$ of total patients. Fever was the chief presentation in all the groups $\mathrm{A}$ [52(100\%)], B [132(100\%)] and C [156(100\%)] with a mean duration of $7.18+/-3.91,8.09+/-4.4$, and 5.26+/-3.49 days in group $\mathrm{A}, \mathrm{B}$ and $\mathrm{C}$ respectively.

Headache was most common in patients with group A 44(80.00\%) followed by group C 120(76.92) whereas it was least in group B (malaria) 64(48.48). This difference between group $A$ and $B$ is statistically significant $(\mathrm{p}=$
.00007) while that in between group A and $\mathrm{C}(\mathrm{p}=$ $.2394)$ is comparable .Generalized body ache symptom was presenting complaint in $82.05 \%$ of group $\mathrm{C}$ patients followed by $46.15 \%$ cases of group A and $9.09 \%$ of group B patients. Pain in the joints was present in group $\mathrm{C}(61.53 \%)$ patients followed by group A $(15.3 \%)$ patients. No patients of group B had joint pain.

Bleeding manifestations in the form of purpuric rashes over skin, melaena, epistaxis were present in $8(15.38 \%)$ cases of co infection, $4(3.03 \%)$ cases of malaria (Grp B)1 and 32(20.51\%) cases of dengue (Grp C). Bleeding manifestations were significantly more in group $\mathrm{A}$ as compared to group B $(\mathrm{p}=0.0048)$ but was not different significantly with group $\mathrm{C}(\mathrm{p}=0.5428)$, hence, comparable with dengue.

Table 2. Clinical features of various groups in our study.

\begin{tabular}{|c|c|c|c|c|c|c|c|c|c|}
\hline & $\begin{array}{c}\text { GROUP } \\
\mathrm{A}(\mathrm{Co}- \\
\text { infection })\end{array}$ & \multirow[t]{2}{*}{$\%$} & \multirow{2}{*}{$\begin{array}{c}\begin{array}{c}\text { GROUP } \\
\text { B } \\
\text { (Malaria) }\end{array} \\
\mathrm{N}=132\end{array}$} & \multirow[t]{2}{*}{$\%$} & \multirow{2}{*}{$\begin{array}{c}\text { GROUP } \\
\text { C } \\
\text { (Dengue) } \\
\mathrm{N}=156\end{array}$} & \multirow[t]{2}{*}{$\%$} & \multicolumn{2}{|c|}{$\mathrm{P}$ value } \\
\hline & & $\mathrm{N}=52$ & & & & & & $A \times B$ & $\mathrm{~A} \times \mathrm{C}$ \\
\hline \multicolumn{2}{|c|}{ FEVER } & 52 & & 132 & & 156 & 100 & - & - \\
\hline \multicolumn{2}{|c|}{ HEADACHE } & 44 & 80 & 64 & 48.48 & 120 & 76.92 & 0.00007 & 0.23949 \\
\hline \multicolumn{2}{|c|}{ BODYACHE } & 24 & 46.15 & 12 & 9.09 & 128 & 82.05 & 0.00001 & 0.00001 \\
\hline \multicolumn{2}{|c|}{ JOINT PAIN } & 8 & 15.38 & 0 & 0 & 96 & 61.53 & - & 0.00001 \\
\hline \multicolumn{2}{|c|}{$\begin{array}{l}\text { ABDOMINAL SYMPTOM } \\
\text { AND SIGN }\end{array}$} & 20 & 38.46 & 32 & 24.24 & 64 & 46.03 & 0.0000 & 0.8705 \\
\hline \multicolumn{2}{|c|}{ BLEEDING } & 8 & 15.38 & 4 & 3.03 & 32 & 20.51 & 0.0048 & 0.5428 \\
\hline CNS & Altered Sensorium & 0 & 0 & 12 & 9.09 & 2 & 1.28 & 0 & 0 \\
\hline \multicolumn{2}{|c|}{ HYPOTENSION } & 3 & 5.35 & 4 & 3.03 & 28 & 17.59 & 0.381865 & 0.032697 \\
\hline \multicolumn{2}{|c|}{ REPIRATORY DISTRESS } & 4 & 7.69 & 20 & 15.15 & 4 & 2.56 & 0.2688 & 0.095846 \\
\hline
\end{tabular}

Abdominal symptoms and sign in the form of nausea and vomiting, pain abdomen, hepatosplenomegaly was present maximum in Group $\mathrm{C}$ (46.03\%) followed by Group A (38.46\%) and then Group B (24.24\%). These abdominal findings were comparable between co infection and dengue group.

Out of 340 patients, $35(10.29 \%)$ cases were in hypotension (BP $<90 / 60 \mathrm{mmHg}$ ) on admission.
Of these 28 patients were from group $\mathrm{C}$ followed by 4 cases in Group B and 3 cases in Group A.

Respiratory distress in the form of acute lung injury or ARDS was present in 28 patients. Of these maximum cases were in Group B (20) followed by group $\mathrm{A}(4)$ and $\mathrm{C}(4)$. This difference was statistically not significant.

Enchephalitis due to dengue virus is rare but there are case reports which have documented this 
finding. In our study also Enchepahalitis was seen in $1.28 \%$ cases of Group $\mathrm{C}$ whereas Cerebral malaria was present in 12(9.09\%) of Group B cases. Of these three patients expired.

\section{Laboratory Parameters}

Table 3 shows various haematological abnormalities in different groups. Out of 340 total cases, severe anemia (i.e. haemoglobin $<7 \mathrm{mg} \%$ ) was seen in $40(11.76 \%)$ patients. Severe anemia was seen in $23.07 \%$ cases of Group A, $15.15 \%$ cases of Group B, and only $5.12 \%$ cases of Group $\mathrm{C}$ cases. Hematocrit levels were low in group A and $\mathrm{B}$ whereas it was elevated in group $\mathrm{C}$.

Table 3. Hematological parameters of cases in our study.

\begin{tabular}{|c|c|c|c|c|c|c|c|}
\hline & & \multicolumn{2}{|c|}{$\begin{array}{l}\text { GROUP A(Co- } \\
\text { infection })\end{array}$} & \multicolumn{2}{|c|}{ GROUP B (Malaria) } & \multicolumn{2}{|c|}{ Group C (Dengue) } \\
\hline & & $\mathrm{N}=52$ & $\%$ & $\mathrm{~N}=132$ & $\%$ & $\mathrm{~N}=156$ & $\%$ \\
\hline \multicolumn{2}{|l|}{ Duration of fever } & \multicolumn{2}{|c|}{$7.18+/-3.91$} & \multicolumn{2}{|c|}{$8.09+/-4.4$} & \multicolumn{2}{|c|}{$5.26+/-3.49$} \\
\hline \multirow{3}{*}{ Heamoglobin } & $<7 \mathrm{mg} / \mathrm{dl}$ & 12 & 23.07 & 20 & 15.15 & 8 & 5.12 \\
\hline & $\begin{array}{c}7.0-10 \\
\mathrm{mg} / \mathrm{dl}\end{array}$ & 28 & 53.84 & 60 & 45.45 & 34 & 21.79 \\
\hline & $>10 \mathrm{mg} / \mathrm{dl}$ & 12 & 23.07 & 52 & 39.4 & 114 & 73.07 \\
\hline \multirow[t]{3}{*}{ Hematocrit (\%) } & $<20$ & 8 & 15.38 & 16 & 12.12 & 4 & 2.56 \\
\hline & $20-40$ & 40 & 76.92 & 92 & 69.69 & 56 & 35.89 \\
\hline & $>40$ & 4 & 7.69 & 24 & 18.18 & 96 & 61.53 \\
\hline \multicolumn{2}{|c|}{ TLC (No./mm3) } & \multicolumn{2}{|c|}{$6661+/-2842$} & \multicolumn{2}{|c|}{$9189+/-5605$} & \multicolumn{2}{|c|}{$5000+/-2719$} \\
\hline \multirow{4}{*}{$\begin{array}{l}\text { Platelets } \\
\text { (No./mm3) }\end{array}$} & $\begin{array}{c}20000- \\
50000\end{array}$ & 20 & 38.46 & 48 & 36.36 & 108 & 82.05 \\
\hline & $\begin{array}{l}50001- \\
100000 \\
\end{array}$ & 28 & 53.85 & 44 & 33.34 & 40 & 25.64 \\
\hline & $\begin{array}{c}100001- \\
150000\end{array}$ & 4 & 7.69 & 32 & 24.24 & 8 & 5.12 \\
\hline & $>150000$ & - & - & 8 & 6.06 & - & - \\
\hline
\end{tabular}

Thrombocytopenia was present in all the groups. Out of 340 patients, 332 patients (i.e.97.64\%) had thrombocytopenia (platelet count $<150000 / \mu \mathrm{L}$ ). It was present in all the patients of Group A and C while in group B it was seen in $93.93 \%$ cases. Severe thrombocytopenia $(<50000)$ was most commonly seen in dengue monoinfection group $(\mathrm{C})(82.05 \%)$, while platelet count between 50000 - 100000 was mostly seen in Group A $(53.85 \%)$. Mean leucocyte count in Group A (6661+- 2842) was lesser than Group B (9189+$5605)$ but higher than Group C (5000+-2719). There were no other important differences in the haematological profile. 


\section{JMSCR Vol||04||Issue||12||Page 15116-15127||December}

Table4. Biochemical parameters of cases in our study

\begin{tabular}{|c|c|c|c|c|c|c|c|c|c|}
\hline & \multicolumn{2}{|c|}{$\begin{array}{l}\text { GROUP A(Co- } \\
\text { infection) }\end{array}$} & \multicolumn{2}{|c|}{$\begin{array}{l}\text { GROUP B } \\
\text { (Malaria) }\end{array}$} & \multicolumn{2}{|c|}{ Group C (Dengue) } & \multicolumn{2}{|c|}{$P$ value } \\
\hline & & $\mathrm{N}=52$ & $\%$ & $\mathrm{~N}=132$ & $\%$ & $\mathrm{~N}=156$ & $\%$ & $\mathrm{~A} \times \mathrm{B}$ & $\mathrm{A} \times \mathrm{C}$ \\
\hline \multirow{2}{*}{$\begin{array}{l}\text { S. } \\
\text { BILIRUBIN }\end{array}$} & NORMAL & 44 & 84.16 & 72 & 54.54 & 92 & 58.97 & \multirow[b]{2}{*}{0.000142} & \multirow[b]{2}{*}{0.000763} \\
\hline & RAISED $(>1.3 \mathrm{mg} / \mathrm{dl})$ & 8 & 15.38 & 60 & 45.45 & 64 & 41.02 & & \\
\hline \multirow[t]{2}{*}{ SGPT } & $\mathrm{N}(10-40 \mathrm{U} / \mathrm{L})$ & 16 & 30.76 & 72 & 54.54 & 36 & 23.07 & \multirow[b]{2}{*}{0.003648} & \multirow[b]{2}{*}{0.267257} \\
\hline & RAISED & 36 & 69.23 & 60 & 45.45 & 120 & 76.92 & & \\
\hline \multirow[t]{2}{*}{ SGOT } & $\mathrm{N}(10-40 \mathrm{U} / \mathrm{L})$ & 12 & 23.07 & 70 & 53.03 & 20 & 12.82 & \multirow[b]{2}{*}{0.000233} & \multirow[b]{2}{*}{0.075856} \\
\hline & RAISED(41 - $120 \mathrm{U} / \mathrm{L})$ & 40 & 76.92 & 62 & 46.96 & 136 & 87.17 & & \\
\hline \multirow[t]{2}{*}{ ALK PO4 } & NORMAL & 24 & 46.15 & 56 & 42.42 & 32 & 20.51 & \multirow[b]{2}{*}{0.645865} & \multirow[b]{2}{*}{0.000306} \\
\hline & RAISED(>147IU/L) & 28 & 53.84 & 76 & 57.57 & 124 & 79.48 & & \\
\hline \multirow[t]{2}{*}{ S. CREAT } & $\begin{array}{l}\text { NORMAL }(0.5 \\
1.5 \mathrm{mg} / \mathrm{dl})\end{array}$ & 48 & 92.3 & 84 & 63.63 & 132 & 84.96 & \multirow[t]{2}{*}{0.000101} & \multirow[t]{2}{*}{0.15929} \\
\hline & RAISED $(1.6-3 \mathrm{mg} / \mathrm{dl})$ & 4 & 7.96 & 48 & 36.36 & 24 & 15.38 & & \\
\hline
\end{tabular}

Biochemical parameters revealed hepatic involvement in all the Groups. Hyperbilirubinemia (> $1.3 \mathrm{mg} / \mathrm{dl}$ ) was seen mostly in Group B (45.45\%) followed by Group C (41.02\%) and A $(15.38 \%)$ whereas raised SGPT (>40IU/L) and SGOT (>4IU/L) were seen mostly in Group $\mathrm{C}(76.92 \%, 87.17 \%$ respectively) and $\mathrm{A}(69.23 \%$, $76.92 \%$ respectively) followed by Group B (45.45\%, 46.96\% respectively).

Renal involvement ( $\mathrm{S}$. Creatinine > $1.6 \mathrm{mg} / \mathrm{dl}$ ) was seen predominantly in Group B $(36.36 \%)$ followed by $15.38 \%$ in Group C and $14.28 \%$ in Group A.

Plasmodium falciparum, P.vivax, and mixed species infection ( $P$. falciparum $+P$. vivax) was found in 12(23.07\%), $32(61.53 \%)$, and 8
(15.38\%) cases respectively among co-infections. Among the patients of malaria mono-infection $P$. falciparum, $P$. vivax and mixed species infection was found in $20(15.15 \%), 100(75.75 \%)$ and 12 $(9.09 \%)$ patients.

Out of total 340 patients, $3(0.882 \%)$ expired and all the mortality was seen Group B. No expiry was seen in Group A and C.

Table 5. Table showing outcome of cases in our study

\begin{tabular}{|l|c|c|c|}
\hline Out come & $\begin{array}{c}\text { GROUP A(Co- } \\
\text { infection) }\end{array}$ & $\begin{array}{c}\text { GROUP B } \\
\text { (Malaria) }\end{array}$ & $\begin{array}{c}\text { Group C } \\
\text { (Dengue) }\end{array}$ \\
\hline Expired & 0 & 3 & 0 \\
\hline Discharged & 52 & 129 & 156 \\
\hline
\end{tabular}

Graph 2. Graph showing outcome of cases in our study

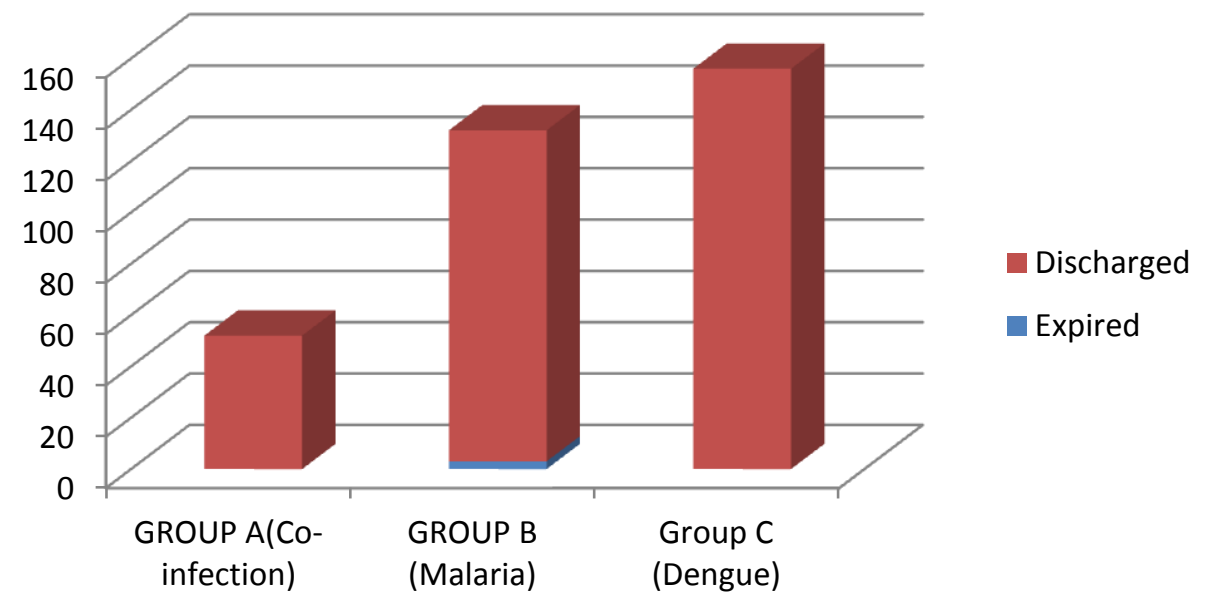




\section{Discussion}

In our study we found a high (25\%) prevalence of the co-infection, among those with dengue. In Pakistan, however, the prevalence found was as high as $23.2 \%{ }^{[18]}$. In Brazil, a prospective study performed in 2009 on 132 patients with vivax malaria found 11 co-infected and the prevalence was $8.3 \%{ }^{[19]}$. In the French Guiana, the prevalence of co-infection was $7.1 \%$ (17 of 238) among patients with dengue ${ }^{[11]}$. Thus, the prevalence of co-infection may fluctuate, depending on local endemicity. In these studies, the prevalence was estimated on hospitalized patients; therefore it could not be extrapolated to the community-based level.

In the present study, P. Vivax was present in majority of the cases $(61.53 \%)$. However, $P$. falciparum and mixed ( $P$. vivax and $P$. falciparum) infection was found in 12 and 8 cases respectively. Similarly Plasmodium vivax was the common species found in both French Guiana ${ }^{[10]}$ and Pakistan ${ }^{[18]}$. In the former study $P$. vivax was found in $63.9 \%$ and P. falciparum in $33.8 \%$ cases where as in the latter P. vivax was found in $96.2 \%$ (25 of 26) cases. This is due to the species prevalence in a particular locality.

In our study co-infected group followed similar pattern [like male predominance, 21- 30 years as commonest age group, and maximum cases from rural areas] to that of both mono-infection and this finding is statistically similar.

The clinical features of concurrent infection had a mixed presentation of both dengue mono-infection and malaria mono-infection. Therefore clinically it is difficult to diagnose concurrent dengue and malaria. Features like headache with retroorbital pain, abdominal symptoms (pain, nausea and vomiting) and bleeding manifestation were statistically similar to dengue mono-infection whereas hypotension, respiratory symptoms were more like malaria mono-infecton.

Symptom analysis of all the patients showed that fever was the commonest symptom $(100 \%)$ in coinfected group and both mono-infection groups. The duration of fever was longer in Co- infected patients and they were hospitalized more frequently than dengue patients but lesser than malaria mono-infection group. That means that a patient with the diagnosis of dengue presenting with prolonged evolution should raise the suspicion of malaria co-infection. Almost Similar findings were seen in studies by M.K. Mohapatra et al ${ }^{[7]}$ Abbasi A et al ${ }^{[5]}$. Loïc Epelboin et al ${ }^{[11]}$ also has similar finding but differs in that the duration of fever in co-infected group was higher than both the groups.

Bleeding is reported as an infrequent finding in malaria, despite common platelet depletion ${ }^{\text {[20] [21]. }}$. Conversely, bleeding is the most feared complication of dengue fever, where in addition to platelet depletion, virus-induced endothelial and liver injury concur to the risk of coagulopathy [22] [23] [24]. In our study severe thrombocytopenia (platelets count $<20,000 / \mathrm{mm} 3$ ) was predominantly seen in dengue mono-infection group whereas it was similar in both malaria mono-infection and co infection group, but bleeding manifestation was uncommon in malaria mono-infection group, and was significantly present in the form of rash and maleana in both co infected and dengue mono-infection group. This finding is in accordance to several studies [5] [7] [11] [13]. This suggests a possible synergistic pathogenic mechanism, which could be related to both capillary fragility and coagulation disorders.

Headache in co infected patients followed the pattern similar to dengue mono infection group. It was moderate to severe in intensity associated with retro orbital pain in majority of the patients. Arthralgia was present in few patients of co infected group as compared to dengue mono infection group while not a single patient in malaria mono-infection group had arthralgia.

Hypotension, a well known clinical feature in dengue shock syndrome was present chiefly in $17.59 \%$ of dengue mono-infection group but it was found only in $5.35 \%$ of co infected patients. This feature in co infected patients was comparable to that of malaria mono-infection. 
Dyspnoea was frequent in all groups, particularly in malaria followed by co-infected patients. Dyspnoea is an early clinical feature of plasma leakage and, in dengue, may be due to fluid accumulation in the pleural cavity ${ }^{[25]}{ }^{[26]}$. In malaria, dyspnoea is due to acute lung injury leading to acute lung edema ${ }^{[27]}$. which is one of the severity criteria for falciparum malaria ${ }^{[28]}$. In a study conducted in Timor East, one patient coinfected with falciparum malaria and dengue presented respiratory distress with radiographic findings compatible with the presentation of acute lung injury ${ }^{[29]}$. The clinical management of these cases is difficult, as the inappropriate fluid therapy for dengue treatment may induce fluid overload and large fluid effusion to the lungs.

CNS involvement was not found in any patient of co infected group whereas CNS involvement in the form of cerebral malaria is one of the severities not only for falciparum ${ }^{[28]}$ malaria but there are reports in which $p$. vivax too is presenting with such severe clinical features ${ }^{[32-35]}$. In our study $9.09 \%$ patients with malaria monoinfection presented with cerebral malaria out which, $3(0.882 \%)$ patients expired. Dengue encephalopathy is a well-recognized entity with the incidence ranging from 0.5 to $6.2 \%$ [30] [43]. The possible mechanisms are deranged electrolytes, liver dysfunction (hepatic encephalopathy), cerebral hypo perfusion (shock), cerebral edema (vascular leak), and intracranial bleeding due to thrombocytopenia or coagulopathy, which is secondary to hepatic dysfunction ${ }^{[31]}$. There are subsets of patients in whom the cause for neurological injury remains unknown even after excluding the above-mentioned indirect mechanisms.

Anaemia was more frequent in patients with dual infection. Haematological profile reveal that severe anemia was present both in co infected group and malaria mono-infection group to a significant extent $(23.05 \%$ and $15.15 \%$ respectively) whereas only $5.12 \%$ patients with dengue mono-infection were present with severe anemia $(\mathrm{Hb}<7 \mathrm{mg} / \mathrm{dl})$. Similar finding was reported in a study from Pakistan in which co infected and malaria group patient had lower haemoglobin as compared to dengue monoinfection group ${ }^{[5][11]}$. Similarly Haematocrit levels were lower in co infected and malaria group where as it was elevated in dengue mono-infection patients due to plasma leakage syndrome ${ }^{[25]}$. An explanation for this fact can be attributed to malaria-induced anemia, a common complication in vivax malaria ${ }^{[36]}$. For this reason, the malaria clinical manifestation may be a confounder for health care professionals during the interpretation and application of dengue severity criteria, in areas where both diseases occur. The proper clinical management of co-infected patients may be compromised due to delay in investigations or misinterpretation, and inappropriate treatment may result in fatal complications ${ }^{[37][38]}$.

In our study, moderate elevation of aminotransferase was seen in all the three groups including co infected group and this elevation in co infected group was comparable to that of dengue mono-infection group. Hyperbilirubinemia $(>1.3 \mathrm{mg} / \mathrm{dl})$ was predominantly present in malaria mono-infection group followed by dengue monoinfection group and least in co infected group. Hyperbilirubinemia $(>1.3 \mathrm{mg} / \mathrm{dl})$ was predominantly present in malaria mono-infection group followed by dengue mono-infection group and least in co infected group. These findings suggest that hepatic cell injury rather than cholestatic injury is the predominant mechanism involved in the pathology of co infected infection.

Acute renal failure is one of the commonest cause in severe malaria patients of our region. In a study from India, acute kidney injury was seen in $16.6 \%$ patients with $\mathrm{P}$. falciparum and $12.3 \%$ patients with P.vivax ${ }^{[35]}$. The possible pathogenic factors are renal damage through renal hypo perfusion or endothelial injury through release of various circulating substances (intravascular haemolysis and sepsis). As far as dengue is concerned Lizarraga KJ et al ${ }^{[39]}$ in his study Dengueassociated kidney disease concluded that Dengue infection has been associated with a variety of 
renal disorders. Acute renal failure, hematuria, proteinuria, and glomerulonephritis have been reported during or shortly after acute dengue infection. It complicates severe dengue infection in $2-5 \%$ of the cases and carries a high mortality rate ${ }^{[40]}$. Studies on renal injury in patients co infected with dengue and malaria to the best of our knowledge are very rare; we found only one case report by Youg K P et al in PubMed ${ }^{[40]}$. In our study renal injury (S.creatinine $>1.5 \mathrm{mg} / \mathrm{dl}$ ) was seen predominantly in malaria group $(36.36 \%)$ followed by dengue mono-infection group (15.38\%) and co infected group (7.96\%). Renal injury in 4 patients with co infection was comparable to that of dengue mono-infection. These patients also had hypotension and respiratory distress. The possible pathogenic factors might be due to synergistic effect of both infection resulting in renal damage through renal hypo perfusion or endothelial injury through release of various circulating substances.

In our study mortality was seen only in malaria mono-infection group [3(0.882\%)]. Death was due to multiorgan dysfunction. They had deranged hepatic, haematological and renal parameters.

\section{Conclusion}

- In our study we found a very high prevalence of co-infection which indicates that it is relatively a common event in our region.

- Patients with the diagnosis of dengue presenting with prolonged fever, severe anemia and respiratory distress should raise the suspicion of malaria co-infection.

- Whereas patients with the diagnosis of malaria presenting with bleeding manifestations, frontal or retro-orbital headache, arthralgia and / elevated haematocrit level should raise the suspicion of dengue coinfection.

- Thus, there is a need for clinicians serving in geographical areas that are endemic to both dengue and dengue to be vigilant of co-infection, especially when the patient presents with atypical clinical features, unexpected laboratory findings or the response to treatment is unsatisfactory and should treated concomitantly for both the infection.

- Rapid diagnostic kits for detecting dengue or malaria are available and are helpful for early diagnosis and treatment of the patients but a single combined rapid diagnostic kit which will detect both dengue and malaria is the need of the hour in our region.

\section{Declarations}

Consent: Written Informed consent was taken from all the patients included in the study.

Acknowledgments: The authors thank Residents of medicine department and Mr Rahul Singh for their help in the acquisition of data.

Funding: No Funding Sources.

Competing interests: The authors declare no competing interests.

\section{References}

1. Charrel RN, Brouqui P, Foucault C, de Lamballerie $\mathrm{X}$ : Concurrent dengue and malaria. Emerg Infect Dis 2005, 11:11531154.

2. Arya CS, Mehta KL, Agarwal N, Agarwal BK, Mathai G, Moondhara A: Episodes of concurrent dengue and malaria. Dengue Bulletin2005, 29:208-209.

3. Manish Bhagat, Sujata Kanhere, Varsha Phadke, and Riya George: Concurrent Malaria and Dengue Fever: A Need for Rapid Diagnostic Methods. J Family Med Prim Care. 2014 Oct-Dec; 3(4): 446448.doi: $10.4103 / 2249 \quad 863.148146$ PMCID: PMC4311362.

4. Deresinski S: Concurrent Plasmodium vivax malaria and dengue. Emerg Infect Dis 1802, 2006:12.

5. Abbasi A, Butt N, Sheikh QH, Bhutto AR, Munir SM, Ahmed SM: Clinical features, diagnostic techniques and management of 
dual dengue and malaria infection. J Coll Physicians Surg Pak 2009, 19:25-29.

6. Ali N, Nadeem A, Anwar M, Tariq WU, Chotani RA: Dengue fever in malaria endemic areas. J Coll Physicians Surg Pak 2006, 16:340-342.

7. M.K. Mohapatra, P. Patra \& R. Agrawala : Manifestation and outcome of concurrent malaria and dengue infection. $\mathrm{J}$ Vector Borne Dis 49, Dec 2012, pp. 262-265.

8. Ward DI: A case of fatal Plasmodium falciparum malaria complicated by acute dengue fever in East Timor. Am J Trop Med Hyg2006, 75:182-185.

9. Thangaratham PS, Jeevan MK, Rajendran R, Samuel PP, Tyagi BK: Dual infection by dengue virus and Plasmodium vivax in Alappuzha District, Kerala, India. Jpn J Infect Dis 2006, 59:211-212.

10. Carme B, Matheus S, Donutil G, Raulin O, Nacher M, Morvan J: Concurrent dengue and malaria in Cayenne Hospital, French Guiana.Emerg Infect Dis 2009, 15:668671.

11. Loïc Epelboin, Matthieu Hanf, Philippe Dussart, Sihem Ouar Epelboin, Félix Djossou, Mathieu Nacher and Bernard Carme: Is dengue and malaria co-infection more severe than single infections? A retrospective matched-pair study in French Guiana. Malaria Journal201211:142 DOI: 10.1186/1475-2875-11-142.

12. Dos Santos Santana V, Lavezzo LC, Mondini A, Terzian AC, Bronzoni RV, Rossit AR, Machado RL, Rahal P, Nogueira MC, Nogueira ML:Concurrent Dengue and malaria in the Amazon region. Rev Soc Bras Med Trop 2010, 43:508-511.

13. Belisa M. L. Magalhães, André M. Siqueira, Márcia A. A. Alexandre, Marcela S. Souza, João B. Gimaque, Michele S. Bastos, Regina M. P. Figueiredo, Gisely C. Melo, Marcus V. G. Lacerda, and Maria P. G. Mourão: P. vivax Malaria and Dengue
Fever Co-infection: A Cross-Sectional Study in the Brazilian Amazon. PLoS Negl Trop Dis. 2014 Oct; 8(10): e3239. Published online $2014 \quad$ Oct 23. doi: 10.1371/journal.pntd.0003239. PMCID: PMC4207662

14. Vitor R R Mendonça, Bruno B Andrade, L igia C L Souza, Belisa M L Magalhães, M aria P G Mourão, Marcus V G Lacerda and Manoel Barral-Netto : Unravelling the patterns of host immune responses in Plasmodium vivax malaria and dengue coinfection. Malaria Journal 201514:315 DOI: 10.1186/s12936-015-0835-8.

15. Chaturvedi UC, Mathur A, Kapoor AK, Mehrotra NK, Mehrotra RML. Virological study of an epidemic of febrile illness with haemorrhagic manifestations at Kanpur, India, during 1968. Bull World Health Organ 1970; 43 : 289-93. 23.

16. Chaturvedi UC, Kapoor AK, Mathur A, Chandra D, Khan AM, Mehrotra RML. A clinical and epidemiological study of an epidemic of febrile illness with haemorrhagic manifestations which occurred at Kanpur, India in 1968. Bull World Health Organ 1970; 43 : 281-7

17. Gulati S, Maheshwari A (2007): Atypical manifestations of dengue. Trop Med Int Health 12: 1087-1095.

18. Abbasi ABN, Sheikh QH, Bhutto AR, Munir SM, Ahmed SM (2009): Clinical features, diagnostic techniques and management of dual dengue and malaria infection. J Coll Physicians Surg Pak 19: 25-29.

19. Magalhaes BM, Alexandre MA, Siqueira AM, Melo GC, Gimaque JB: Clinical profile of concurrent dengue fever and Plasmodium vivax malaria in the Brazilian Amazon: case series of 11 hospitalized patients. Am J Trop Med Hyg 87: 11191124.

20. Kochar DK, Das A, Kochar A, Middha S, Acharya J: Thrombocytopenia in 
Plasmodium falciparum, Plasmodium vivax and mixed infection malaria: a study from Bikaner (Northwestern India). Platelets 21: 623-627.

21. Lacerda MV, Mourao MP, Coelho HC, Santos JB (2011) Thrombocytopenia in malaria: who cares?Mem Inst Oswaldo Cruz 106 Suppl 1: 52-63.

22. Mourao MP, Lacerda MV, Macedo VO, Santos JB (2007) Thrombocytopenia in patients with dengue virus infection in the Brazilian Amazon. Platelets 18: 605-612.

23. Alonzo MT, Lacuesta TL, Dimaano EM, Kurosu T, Suarez LA, et al. (2012) Platelet apoptosis and apoptotic platelet clearance by macrophages in secondary dengue virus infections. J Infect Dis 205: 1321-1329.

24. Costa VV, Fagundes CT, Souza DG, Teixeira MM (2013) Inflammatory and Innate Immune Responses in Dengue Infection: Protection versus Disease Induction. Am J Pathol 182: 1950-1961.

25. WHO (2009) Dengue: Guidelines for diagnosis, treatment, prevention and control. Geneva, Switzerland.

26. Sen MK, Ojha UC, Chakrabarti S, Suri JC (1999) Dengue hemorrhagic fever (DHF) presenting with ARDS. Indian J Chest Dis Allied Sci 41: 115-119.

27. Lomar AV, Vidal JE, Lomar FP, Barbas CV, de Matos GJ, et al. (2005) Acute respiratory distress syndrome due to vivax malaria: case report and literature review. Braz J Infect Dis 9: 425-430.

28. World Health Organization (2006) Guidelines for the treatment of malaria. Geneva, Switzerland.

29. Ward DI (2006): A case of fatal Plasmodium falciparum malaria complicated by acute dengue fever in East Timor. Am J Trop Med Hyg 75: 182-185.

30. Misra UK, Kalita J, Syam UK, Dhole TN : Neurological manifestations of dengue virus infection. J Neurol Sci. 2006 May $15 ; 244(1-2): 117-22$.
31. Cho Naing, Maxine A. Whittaker, Victor Nyunt Wai, and Joon Wah Mak. Is Plasmodium vivax Malaria a Severe Malaria?: A Systematic Review and MetaAnalysis. PLoS Negl Trop Dis. 2014 Aug; 8(8): e3071. Published online 2014 Aug 14. doi: 10.1371/journal.pntd.0003071 PMCID: PMC4133404.

32. Singh H, Parakh A, Basu S, Rath B. Plasmodium vivax malaria: is it actually benign?. J Infect Public Health. 2011 Jun;4(2):91-5. doi: 10.1016/j.jiph.2011.03.002. Epub 2011 May 26.

33. Vivek B. Kute, Hargovind L. Trivedi, Aruna V. Vanikar, Pankaj R. Shah, Manoj R. Gumber, Himanshu V. Patel,Jitendra G. Goswami, and Kamal V. Kanodia. Plasmodium vivax Malaria-associated Acute Kidney Injury, India, 2010-2011. Emerg Infect Dis. 2012 May; 18(5): 842845. PMCID: PMC3358071.

34. D. K. Kochar, A. Das, S. K. Kochar et al., "Severe Plasmodium vivax malaria: a report on serial cases from Bikaner in northwestern India," American Journal of Tropical Medicine and Hygiene, vol. 80, no. 2, pp. 194-198, 2009.

35. Verma RK, Giri R, Singh N,Verma S, Srivastav V : A Study ON Clinical Presentation and Outcome of Malaria from an Underreported, P.vivax Predominant Region of North India. Sch. J. App. Med. Sci., 2016; 4(1C):233-243.

36. Costa AP, Bressan CS, Pedro RS, Vallsde-Souza R, Silva S, et al. (2010) Delayed diagnosis of malaria in a dengue endemic area in the Brazilian extra-Amazon: recent experience of a malaria surveillance unit in state of Rio de Janeiro. Rev Soc Bras Med Trop 43: 571-574.

37. Ward DI (2006) A case of fatal Plasmodium falciparum malaria complicated by acute dengue fever in East Timor. Am J Trop Med Hyg 75: 182-185. 
38. Simmons CP, Farrar JJ, Nguyen vV, Wills B (April 2012). "Dengue". N Engl J Med366 (15): 1423-32. doi:10.1056/NEJMra1110265.PMID 22494122.

39. Lizarraga KJ, Nayer A: Dengue-associated kidney disease. J Nephropathol. 2014;3 (2):57-62. doi: 10.12860/jnp.2014.13. Epub 2013 Dec 28. Review. PMID: 24772398.

40. Yong KP, Tan BH, Low CY: Severe falciparum malaria with dengue coinfection complicated by rhabdomyolysis and acute kidney injury: an unusual case with myoglobinemia, myoglobinuria but normal serum creatine kinase. BMC Infect Dis.2012 Dec 20;12:364.doi: $0.1186 / 1471-2334-12-364$. PubMed PMID: 23256803; PubMed Central PMCID: PMC3557149.

41. Anand AC, Puri P (2005): Jaundice in malaria. J Gastroenterol Hepatol 20: 13221332.

42. Seneviratne SL, Malavige GN, de Silva HJ (2006): Pathogenesis of liver involvement during dengue viral infections. Trans $\mathrm{R}$ Soc Trop Med Hyg 100: 608-614.

43. Gulati S, Maheshwari A (2007): Atypical manifestations of dengue. Trop Med Int Health 12: 1087-1095.

44. Varatharaj A: Encephalitis in the clinical spectrum of dengue infection. Neurol India. 2010 Jul-Aug; 58(4):585-91.

45. Malaria, National Vector Borne Disease Control Programme (NVBDCP). Available from: http://www.nvbdcp.gov.in/malaria3.html. [Last accessed on 2015 Dec 27]. 